\title{
Annotations
}

\section{Clinical significance of gastro-oesophageal reflux}

Reflux of gastric contents into the oesophagus is a common happening in infants. This has long been known from clinical observation (as judged by the frequency of regurgitation) and from fluoroscopic studies. Of recent years many investigatory procedures in addition to conventional radiology have been devised and used increasingly to study gastrooesophageal function and reflux in infantsoesophageal manometry, acid reflux tests, 24-hour intraluminal oesophageal $\mathrm{pH}$ probe monitoring, and gastro-oesophageal scintigraphy. These studies have confirmed that reflux is an exceedingly common event in early infancy. This is not unexpected since the intra-abdominal segment of oesophagus is often virtually non-existent at this age, ${ }^{1}$ and as a result the important mechanical antireflux effect of having the terminal oesophagus exposed to intra-abdominal pressure is lost. ${ }^{2-4}$ As the abdominal segment of oesophagus lengthens, so an effective antireflux barrier is gradually established by about 3 months of age. ${ }^{5}$ Reflux, however, will continue to occur intermittently under physiological conditions at times of transient inappropriate complete gastrooesophageal sphincteric relaxation. ${ }^{67}$ It is, therefore, imperative that gastro-oesophageal reflux should be initially regarded, especially in early infancy, as constituting a physiological event and should only be accorded sinister clinical importance when very compelling reasons for doing so exist.

The application, often for prolonged periods, of these refined and more sensitive techniques to the investigation of widely different clinical disorders has resulted in gastro-oesophageal reflux being implicated aetiologically in a variety of conditions apart from persistent vomiting and failure to thrive for example asthma, recurrent bronchitis and pneumonia, apnoeic periods in the newborn, cyanotic attacks, 'near miss' sudden infant death syndrome, rumination, torticollis and abnormal movements of head and neck, and neuropsychiatric disturbances. Gastro-oesophageal reflux may be of clinical importance in some of these disorders but much more commonly it is likely to be a coincidental physiological observation. It is noteworthy that except for pulmonary infections none of these disorders occurred with undue frequency in a prospective 35 year study of 710 children with a partial thoracic stomach (hiatal hernia) and gastrooesophageal incompetence, undertaken by the author.

It is obvious that the discovery of reflux in a patient does not necessarily establish a causal relation with the disorder under investigation. Yet there has been a tendency during the past few years for some investigators to consider all degrees of gastro-oesophageal reflux as potentially harmful. This has resulted in over emphasis of the clinical importance of reflux in small infants-a particularly regrettable interpretation when taken to the point of surgical intervention. The distinction between what is acceptable as physiological and what might reasonably be called pathological (that is clinically significant) reflux is therefore clearly of paramount clinical importance.

It has become commonplace for investigators to regard reflux per se as constituting a distinct clinical entity without regard to its causation. Yet knowledge of the pathogenesis of reflux is all important in terms of its clinical importance and management. Pathological reflux occurs when there is a breakdown in the antireflux barrier resulting from a functional abnormality of one or other of its two major components, namely the gastro-oesophageal sphincter and the intra-abdominal oesophagus. ${ }^{8}$ In clinical practice this pathological breakdown is almost always attributable to displacement of the sphincter into the thorax whereby the antireflux effect of having the terminal oesophagus exposed to intra-abdominal pressure is lost (Figure). Herein lies the importance of thoroughly investigating children with reflux for the presence of an underlying partial thoracic stomach, since identification of this structural abnormality provides the most important and reliable means of distinguishing pathological from physiological reflux. Examination by barium swallow and fluoroscopy has long been the accepted routine method of investigating for gastrooesophageal reflux and this is likely to remain so. Radiological examination when undertaken by a knowledgeable and experienced paediatric radiologist has the important additional advantage over all other forms of investigation in that it also enables an underlying partial thoracic stomach to be identified.

Largely as a result of the emphasis placed on detecting reflux by non-radiological methods, it has become customary to attach little or no importance to the presence or absence of a partial thoracic stomach in children with reflux. Failure to attribute importance to this abnormality coupled with the general acceptance of reflux as a specific clinical entity has led to the mistaken assumption that observations recorded in patients with a partial 


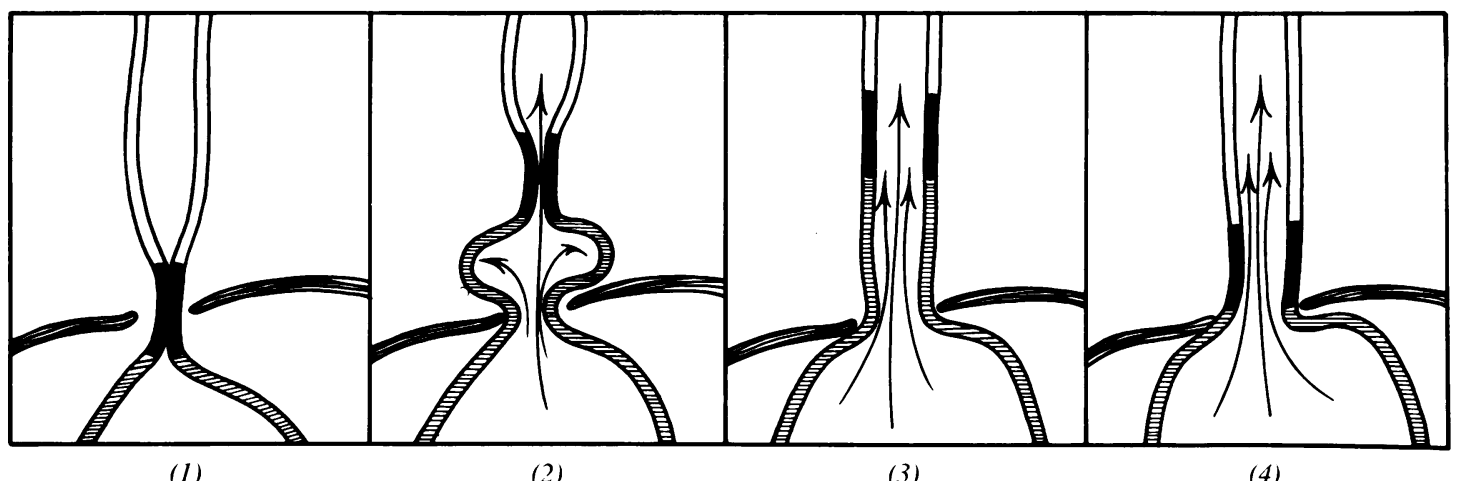

(1)

(2)

(3)

(4)

Figure (1) Normally positioned gastro-oesophageal junction; (2) partial thoracic stomach; (3) partial thoracic stomach masquerading as 'chalasia'; and (4) idiopathic gastro-oesophageal incompetence.

thoracic stomach are equally applicable to all patients with reflux. This is certainly incorrect. For example, not one of over 1000 infants with radiological evidence of reflux in the absence of a partial thoracic stomach, seen by the author over a period of more than 30 years, has developed a stricture and none have required surgery. These two observations underline the fact that this is a very much more benign condition than reflux resulting from a partial thoracic stomach. For, if untreated, about $30 \%$ of the children attending hospital with this latter disorder would be likely to suffer from troublesome symptoms beyond 4 years of age, with a further $5 \%$ at risk of developing a reflux stricture. ${ }^{9}$

The occurrence of pathological reflux as an isolated finding on fluoroscopic examination is sometimes referred to as 'chalasia'. Most infants so diagnosed have been shown on later re-examination to have had a previously unrecognised partial thoracic stomach (Figure). ${ }^{10}$ In a few, however, reflux persists as the only abnormality found on repeated fluoroscopic examination. The use of the 'term 'chalasia' to describe this condition is inappropriate for it implies a specific abnormality of sphincteric function when, in effect, the cause is unknown. Obliteration of the abdominal segment of oesophagus resulting from displacement of the gastro-oesophageal junction to the level of the hiatus could well be a more important aetiological factor in these patients. The term 'idiopathic gastrooesophageal incompetence' is preferred when referring to this type of case (Figure).

Gastro-oesophageal reflux is common in infants and in only a small proportion is this of clinical importance. In the vast majority of these latter patients reflux is due to gastro-oesophageal incompetence resulting from a partial thoracic stomach. The radiological finding of a partial thoracic stomach in a child with reflux is, therefore, of the utmost clinical importance since the presence of this structural abnormality affords the most reliable means of distinguishing pathological from physiological reflux. While reflux is relatively easy to record radiologically, a partial thoracic stomach is often difficult to identify. The all important recognition of a partial thoracic stomach in infants with reflux will, therefore, depend not only on an awareness by clinicians and radiologists of its clinical importance but on the availability of a radiologist with experience of this problem.

\section{References}

1 Botha GSM. The gastro-oesophageal region in infants. Arch Dis Child 1958;33:78-94.

2 Edwards DAW. The anti-reflux mechanism: manometric and radiological studies. $\mathrm{Br} J$ Radiol 1961;34:474-87.

3 Johnson HD. The cardia and hiatus hernia. London: Heinemann, 1968:103.

4 DeMeester TR, Wernly JA, Bryant GH, Little AG, Skinner DB. Clinical and in vitro analysis of determinants of gastroesophageal competence. Am J Surg 1979;137:39-46.

5 Boix-Ochoa J, Canals J. Maturation of the lower esophagus. J Pediatr Surg 1976;11:749-56.

${ }^{6}$ Dent J, Dodds WJ, Friedman RH, et al. Mechanism of gastrocsophageal reflux in recumbent asymptomatic human subjects. J Clin Invest 1980;65:256-67.

7 Werlin SL, Dodds WJ, Hogan WJ, Arndorfer RC. Mechanisms of gastroesophageal reflux in children. J Pediatr 1980;97:244-9.

${ }^{8}$ Carré IJ. The gastro-oesophageal anti-reflux mechanism. In: Anderson CM, Burke V, eds. Paediatric gastroenterology. Oxford: Blackwell Scientific Publications, 1975:9-21.

' Carré IJ. The natural history of the partial thoracic stomach ('hiatus hernia') in children. Arch Dis Child 1959;34:344-53.

10 Carré IJ. Anatomy and physiology of the upper gastrointestinal tract in relation to GER and hiatal hernia. In: Gellis SS, ed. Gastroesophageal reflux. Report of the seventy-sixth Ross conference on paediatric research. Columbus, Ohio: Ross Laboratories, 1979:12-22.

I J CARrÉ

The Nuffield Department of Child Health, The Queen's University of Belfast 